\title{
Pulmonary rehabilitation in lymphangioleiomyomatosis: a controlled clinical trial
}

\author{
Mariana S. Araujo ${ }^{1}$, Bruno G. Baldi ${ }^{1}$, Carolina S.G. Freitas ${ }^{1}$, \\ André L.P. Albuquerque ${ }^{1}$, Cibele C.B. Marques da Silva ${ }^{2}$, Ronaldo A. Kairalla ${ }^{1}$, \\ Celso R.F. Carvalho ${ }^{2}$ and Carlos R.R. Carvalho ${ }^{1}$
}

Affiliations: 'Pulmonary Division, Heart Institute (InCor), University of São Paulo Medical School, São Paulo, Brazil. ${ }^{2}$ Physical Therapy, University of São Paulo Medical School, São Paulo, Brazil.

Correspondence: Carlos R.R. Carvalho, Av Dr Eneas de Carvalho Aguiar 44, 5. andar - Sala 1, São Paulo, 05403-000, Brazil. E-mail: crrcarvalhoduol.com.br

ABSTRACT Lymphangioleiomyomatosis (LAM) is a cystic lung disease frequently associated with reduced exercise capacity. The aim of this study was to assess safety and efficacy of pulmonary rehabilitation in LAM.

This controlled clinical trial included 40 patients with LAM and a low physical activity level. The pulmonary rehabilitation programme comprised 24 aerobic and muscle strength training sessions and education. The primary outcome was exercise capacity (endurance time during a constant work rate exercise test). Secondary outcomes included health-related quality of life (St George's Respiratory Questionnaire (SGRQ)), 6-min walking distance (6MWD), dyspnoea, peak oxygen consumption $\left(V^{\prime} \mathrm{O}_{2}\right)$, daily physical activity (pedometer), symptoms of anxiety and depression, lung function and peripheral muscle strength (one-repetition maximum).

The baseline characteristics were well balanced between the groups. The pulmonary rehabilitation group exhibited improvements in the following outcomes versus controls: endurance time (median (interquartile range) $169(2-303) \mathrm{s}$ versus $-33(-129-39) \mathrm{s} ; \mathrm{p}=0.001)$, SGRQ (median (interquartile range) $-8(-16-2)$ versus $2(-4-5) ; \mathrm{p}=0.002$ ) and 6MWD (median (interquartile range) 59 (13-81) $\mathrm{m}$ versus $20(-12-30) \mathrm{m}$; $\mathrm{p}=0.002$ ). Dyspnoea, peak $V^{\prime} \mathrm{O}_{2}$, daily physical activity and muscle strength also improved significantly. No serious adverse events were observed.

Pulmonary rehabilitation is a safe intervention and improves exercise capacity, dyspnoea, daily physical activity, quality of life and muscle strength in LAM.

@ERSpublications

Evaluation of a pulmonary rehabilitation programme in lymphangioleiomyomatosis demonstrates safety and efficacy http://ow.ly/Xmofp

This article has supplementary material available from erj.ersjournals.com

Received: Oct 102015 | Accepted after revision: Jan 112016 | First published online: Feb 252016

Clinical trial: This study is registered at ClinicalTrials.gov with identifier number NCT02009241.

Support statement: This study was partially funded by the São Paulo Research Foundation (FAPESP). The funder did not interfere in this study, including study design, data collection, analysis, interpretation, writing of the manuscript or the decision to submit it for publication.

Conflict of interest: None declared.

Copyright OERS 2016 


\section{Introduction}

Lymphangioleiomyomatosis (LAM) is a rare cystic lung disease that mainly affects young women. The current concept of this disorder defines it as a low-grade, destructive, metastasising neoplasm [1]. Although the available treatments (mTOR inhibitors) might slow disease progression, it remains incurable [2]. Most patients with LAM complain of impaired quality of life and reduced exercise capacity, secondary to airflow obstruction, abnormal diffusion capacity, dynamic hyperinflation, peripheral muscle dysfunction (deconditioning) and pulmonary hypertension [3].

Pulmonary rehabilitation is a comprehensive intervention involving exercise training, education and behaviour changes, designed to improve the physical and psychological conditions of patients with chronic respiratory diseases [4]. Pulmonary rehabilitation improves exercise tolerance, dyspnoea, and quality of life in chronic obstructive pulmonary disease (COPD) [5]. More recently, studies have shown that these benefits might extend to other respiratory diseases, including interstitial lung diseases, asthma and lung cancer [5].

Exertional dyspnoea is an important burden associated with LAM, and many of the suggested underlying mechanisms are similar to those described in COPD. Therefore, we hypothesised that pulmonary rehabilitation would also benefit patients with LAM and aimed to assess the safety and impact of pulmonary rehabilitation on exercise capacity, dynamic hyperinflation, dyspnoea, daily physical activity, health-related quality of life, anxiety and depression, lung function and muscle strength in these patients.

\section{Methods \\ Study design and participants}

This was a non-randomised, controlled, parallel group, open label, single-centre study conducted in São Paulo, Brazil. All patients attending the outpatient clinic of the Pulmonary Division of Hospital das Clinicas, University of São Paulo were evaluated for study participation. Patients had to meet the following criteria: definitive diagnosis of LAM according to European Respiratory Society guidelines [6]; clinical stability, defined as no exacerbations for a minimum of 6 weeks and no change in treatment in the previous 3 months; and a regular physical activity performance below the recommended level (moderate-intensity aerobic physical activity for a minimum of $30 \mathrm{~min}$ on 5 days per week or vigorous-intensity aerobic activity for a minimum of $20 \mathrm{~min}$ on 3 days per week [7]) for at least 4 months prior to the rehabilitation programme.

Patients were excluded for any of the following conditions: lung transplant; musculoskeletal or cognitive disorders that could interfere with testing; severe or uncontrolled heart disease; and class III obesity (body mass index $\geqslant 40 \mathrm{~kg} \cdot \mathrm{m}^{-2}$ ). The protocol was approved by the local research ethics committee and all patients provided written informed consent before enrolment. The study was registered at ClinicalTrials.gov (NCT02009241)

The decision to perform a nonrandomised trial was made due to the rarity of the disease and geographical issues. Because our outpatient clinic is a LAM reference centre in Brazil, we see patients from all regions of the country. Prior to the study, we stated that patients from São Paulo city would be invited to participate in the intervention, whereas patients living outside São Paulo or unable to attend pulmonary rehabilitation for other reasons (e.g. full-time employment) would be invited to participate as controls.

\section{Measurements}

The evaluations performed at each study visit are described in figure 1. Technical information regarding execution of the tests is provided in the online supplementary material.

$\begin{gathered}\text { Clinical evaluation } \\ \text { Dyspnoea assessment } \\ \text { PFTs } \\ \text { Visits }\end{gathered}$
Bncremental CPET
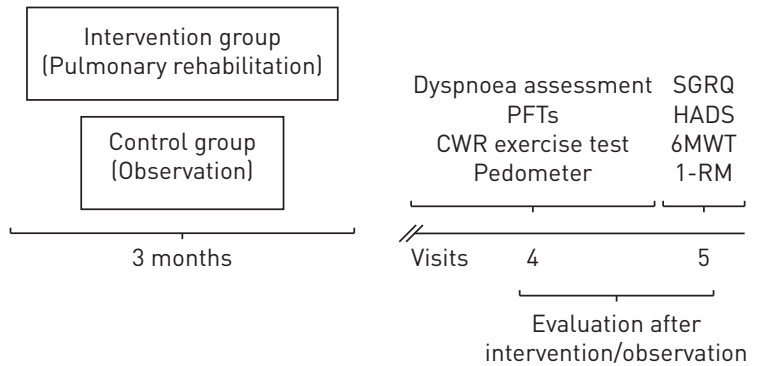

FIGURE 1 Study visits and assessments. PFT: pulmonary function test; CPET: cardiopulmonary exercise test; CWR: constant work rate; SGRQ: St George's Respiratory Questionnaire; HADS: Hospital Anxiety and Depression Scale; 6MWT: 6-min walk test; 1-RM: one-repetition maximum. 
Pulmonary rehabilitation

Pulmonary rehabilitation comprised 24 1-h sessions (twice weekly) divided into $30 \mathrm{~min}$ of treadmill aerobic exercise and $30 \mathrm{~min}$ of muscle strength training. Aerobic training was performed at a heart rate corresponding to two-thirds of the difference between the anaerobic threshold and the respiratory compensation point, determined during an incremental cardiopulmonary exercise test (CPET) [8]. Symptoms of breathlessness and leg discomfort, heart rate and arterial oxygen saturation measured by pulse oximetry $\left(\mathrm{SpO}_{2}\right)$ were monitored every $5 \mathrm{~min}$. Oxygen supplementation was provided when necessary to maintain $\mathrm{SpO}_{2}$ above 90\% [9]. Muscle strength training began with three sets of eight repetitions of each exercise at a workload of $50 \%$ of the one-repetition maximum (1-RM) [10]. Thereafter, the repetitions were progressively increased to three sets of 12 repetitions. When more than 12 repetitions per set could be performed, the training workload was increased [11]. Patients also received education on the following themes: LAM physiopathology and treatment, self-management, exercise physiology, and the importance of physical activity. To have their results analysed, patients were required to complete at least $80 \%(20$ sessions) of the programme.

Controls received educational content equal to that of the intervention group, but were advised not to change their daily routine of physical activity until the end of the trial.

\section{Outcomes}

The primary outcome was the endurance time during the constant work rate (CWR) exercise test. The secondary outcomes were: peak oxygen consumption $\left(V^{\prime} \mathrm{O}_{2}\right)$ during the CWR exercise test; dyspnoea assessed by the modified Medical Research Council dyspnoea scale (mMRC), and the Transitional Dyspnoea Index (TDI) [12]; health-related quality of life using the St George's Respiratory Questionnaire (SGRQ) [13]; symptoms of anxiety and depression using the Hospital Anxiety and Depression Scale (HADS) [14]; daily physical activity assessed using a pedometer; walking distance and desaturation during the 6-min walk test (6MWT); and peripheral muscle strength according to the 1-RM. Safety was assessed by the occurrence of adverse events, including pneumothorax.

\section{Statistical analysis}

Data are reported as mean $\pm \mathrm{SD}$ for variables with normal distributions or as median (interquartile range) for variables with non-normal distributions. The unpaired t-test or Mann-Whitney U-test was used to compare continuous variables. Categorical variables were compared using Fisher's exact test or the Chi-squared test. The paired t-test or Wilcoxon test was used to compare within-subject results. The Spearman correlation coefficient was used to evaluate associations between variables. Differences were considered significant if the p-value was $<0.05$. Data were analysed with SigmaStat, version 3.5 (Systat Software, Inc., San Jose, CA, USA).

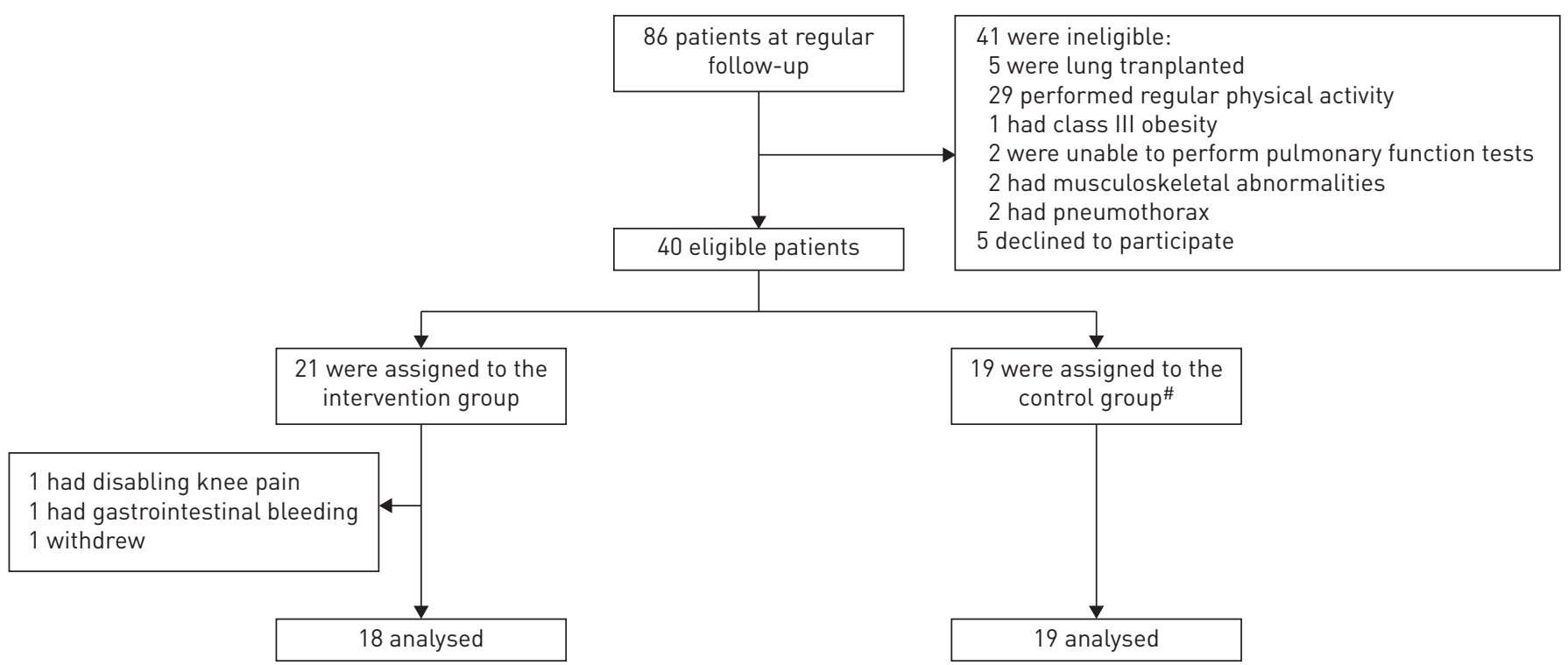

FIGURE 2 Trial profile. * : control group participants lived outside São Paulo or were unable to join the pulmonary rehabilitation group due to working full time or living far away from the hospital. 
TABLE 1 Baseline characteristics of the subjects

\begin{tabular}{|c|c|c|c|c|}
\hline & All subjects & Pulmonary rehabilitation group & Control group & p-value \\
\hline Subjects $n$ & 37 & 18 & 19 & \\
\hline \multicolumn{5}{|l|}{ Clinical characteristics } \\
\hline $\mathrm{BMI} \mathrm{kg} \cdot \mathrm{m}^{-2}$ & $26 \pm 4$ & $26 \pm 4$ & $26 \pm 4$ & 0.61 \\
\hline \multicolumn{5}{|l|}{ Dyspnoea } \\
\hline BDI (total) & $8(7-9)$ & $8(6-9)$ & $8(7-10)$ & 0.40 \\
\hline SGRQ (total) & $37.5 \pm 20.8$ & $40.5 \pm 22.1$ & $34.7 \pm 19.5$ & 0.40 \\
\hline HADS (total) & $13(10-21)$ & $12(10-23)$ & $17(11-20)$ & 0.45 \\
\hline \multicolumn{5}{|l|}{ Pulmonary function tests } \\
\hline FEV1 L & $2.04 \pm 0.84$ & $1.95 \pm 0.84$ & $2.1 \pm 0.80$ & 0.97 \\
\hline FEV1 \% pred & $72 \pm 28$ & $74 \pm 30$ & $70 \pm 27$ & 0.67 \\
\hline $\mathrm{FEV}_{1} / \mathrm{FVC}$ & $0.75(0.57-0.8)$ & $0.77(0.51-0.80)$ & $0.70(0.61-0.82)$ & 0.62 \\
\hline \multicolumn{5}{|l|}{ Incremental CPET } \\
\hline Work rate $\mathrm{W}$ & $77 \pm 33$ & $77 \pm 33$ & $76 \pm 35$ & 0.93 \\
\hline Work rate $\%$ & $58 \pm 24$ & $61 \pm 24$ & $56 \pm 24$ & 0.51 \\
\hline Peak $V^{\prime} \mathrm{O}_{2} \mathrm{~mL} \cdot \mathrm{min}^{-1}$ & $1077 \pm 369$ & $1078 \pm 413$ & $1077 \pm 334$ & 1.0 \\
\hline Peak $V^{\prime} \mathrm{O}_{2} \mathrm{~mL} \cdot \mathrm{kg}^{-1} \cdot \mathrm{min}^{-1}$ & $16.4 \pm 49$ & $16.9 \pm 5.4$ & $15.9 \pm 4.4$ & 0.52 \\
\hline Peak $V^{\prime} \mathrm{O}_{2} \%$ & $72 \pm 23$ & $76 \pm 28$ & $70 \pm 17$ & 0.42 \\
\hline Anaerobic threshold $\%$ peak $V^{\prime} \mathrm{O}_{2}$ & $64 \pm 11$ & $66 \pm 13$ & $62 \pm 9$ & 0.36 \\
\hline Breathing reserve $\%$ & $32 \pm 20$ & $27 \pm 23$ & $38 \pm 16$ & 0.09 \\
\hline Heart rate beats $\cdot \mathrm{min}^{-1}$ & $146 \pm 23$ & $142 \pm 22$ & $151 \pm 24$ & 0.22 \\
\hline $\mathrm{SpO}_{2} \%$ & $95(86-97)$ & $95(83-96)$ & 95 (88-98) & 0.34 \\
\hline Borg dyspnoea & $8(7-9)$ & $9(7-9)$ & $7(7-9)$ & 0.70 \\
\hline Borg leg discomfort & $9(7-10)$ & $10(9-10)$ & $7(6-10)$ & 0.14 \\
\hline
\end{tabular}

\section{Results}

Of the 86 patients followed in our outpatient clinic between December 18, 2013 and January 6, 2015, 40 were eligible for this study (figure 2). 21 and 19 patients were assigned to the intervention (pulmonary rehabilitation) and control groups, respectively. Three patients in the pulmonary rehabilitation group did not complete the programme (figure 2), but only one had an interruption related to the intervention (disabling knee pain). All 18 patients analysed in the pulmonary rehabilitation group completed at least $95 \%$ of the programme. Both groups were well balanced with respect to major clinical characteristics, lung function and exercise capacity (table 1 and table E1). Furthermore, baseline characteristics remained similar even when patients who withdrew before revaluation were included.

\section{Incremental CPET}

All patients achieved the maximum criteria for the incremental CPET [15], which was performed only at baseline. All tests were symptom-limited and the most common reason stated by patients for interrupting exercise was leg fatigue $(12(67 \%)$ in the pulmonary rehabilitation group versus 10 (53\%) of controls; $\mathrm{p}=0.59$ ). $89 \%$ of subjects ( $78 \%$ of the intervention group versus $100 \%$ of controls; $\mathrm{p}=0.05$ ) did not achieve at least $80 \%$ of the predicted maximum work rate, whereas $73 \%$ of patients had a peak $V^{\prime} \mathrm{O}_{2}<84 \%$ of predicted ( $67 \%$ of the intervention group versus $79 \%$ of controls; $\mathrm{p}=0.48$ ). Oxygen desaturation $(>4 \%)$ was observed in $35 \%$ of patients ( $33 \%$ of the intervention group versus $37 \%$ of controls; $\mathrm{p}=0.9$ ), and dynamic hyperinflation was observed in $13(35 \%)$ subjects (7 (39\%) intervention subjects and $6(32 \%)$ controls; $\mathrm{p}=0.9)$. 
TABLE 2 Comparison of changes in variables obtained from CWR exercise testing between the intervention and control groups

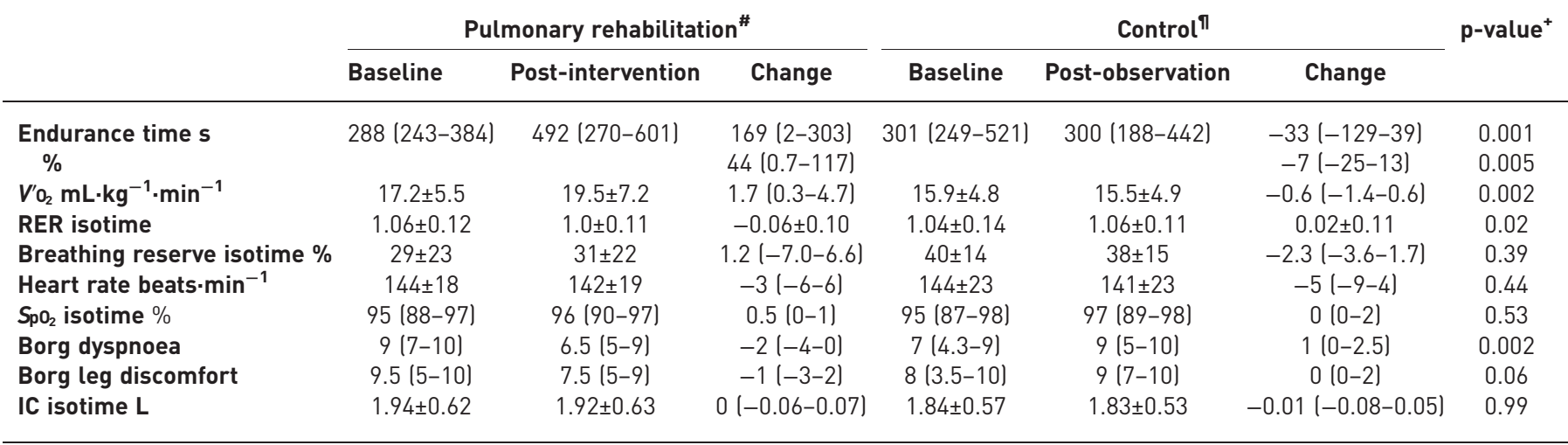

Data are presented as mean \pm SD, or median (interquartile range), unless otherwise stated. CWR: constant work rate; $V^{\prime} O_{2}$ : oxygen consumption; RER: respiratory exchange rate; $\mathrm{SpO}_{2}$ : arterial oxygen saturation measured by pulse oximetry; IC: inspiratory capacity. ${ }^{\#}$ : $\mathrm{n}=18$; ${ }^{\uparrow}$ : $\mathrm{n}=19$; ${ }^{+}: \mathrm{p}$-value refers to the comparison of the change in the variables between groups.

\section{CWR exercise testing}

CWR exercise testing values at baseline did not differ significantly between groups. A clinically meaningful improvement in endurance time was observed after exercise training (>100 s and $>20 \%$ ) (table 2) [16-18]. Figure 3 shows variations in the endurance time for each patient. The pulmonary rehabilitation group also exhibited an increase in peak $V^{\prime} \mathrm{O}_{2}$ and reductions in the respiratory exchange ratio (RER) and dyspnoea in isotime comparisons (table 2 and figure E1). Our time course evaluation during CPET in the intervention group confirmed that symptom reduction occurred even in the early phases of exercise (figure E2). Pulmonary rehabilitation did not change ventilatory, gas exchange or cardiovascular variables.

\section{Dyspnoea}

Before the study, all but two patients complained of dyspnoea. Nevertheless, the majority of patients exhibited a mild degree of dyspnoea, with a median total Baseline Dyspnoea Index score of eight; $56 \%$ of the pulmonary rehabilitation group and $47 \%$ of controls received a mMRC classification of one $(p=0.87)$.

When compared with controls, the pulmonary rehabilitation group exhibited significant reductions in both dyspnoea scales (table 3). A decrease in the mMRC score was observed in seven (39\%) patients in the intervention group, compared with none of the controls $(p=0.003)$. All patients in the pulmonary rehabilitation group had improved TDI total scores, compared with only three (16\%) of the controls $(\mathrm{p}<0.001)$. The pulmonary rehabilitation group showed improvements in all domains of TDI, except the functional impairment domain (figure E3).
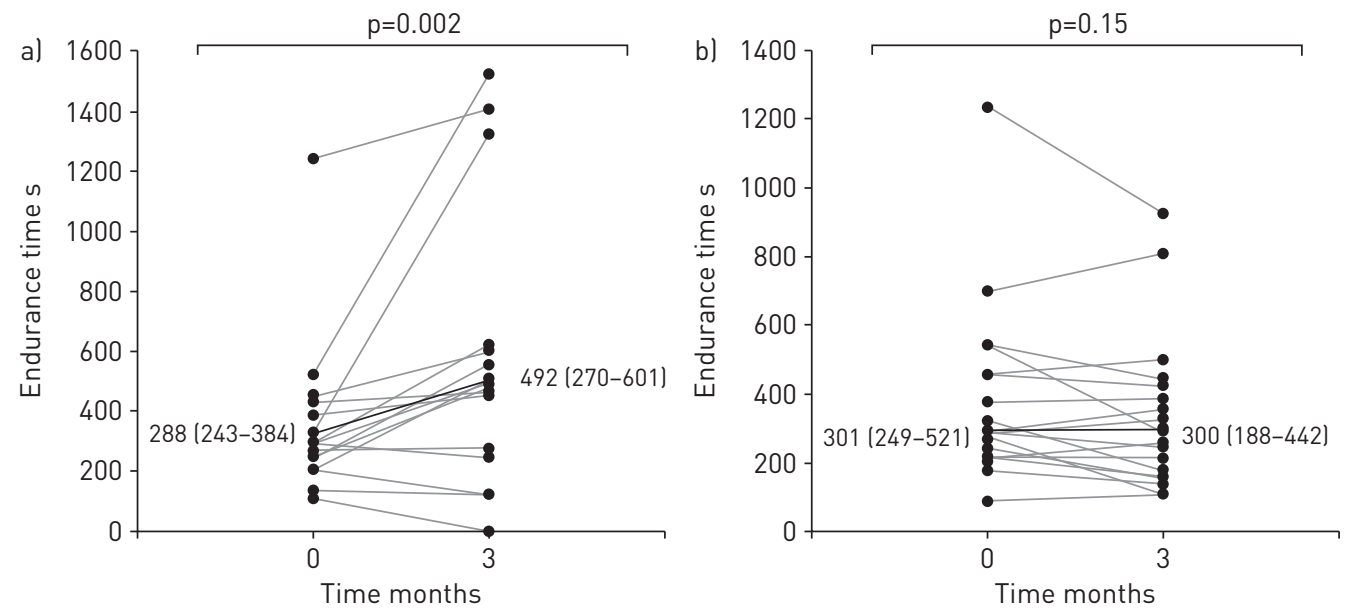

FIGURE 3 Variation in endurance time for each subject. a) Intervention group. b) Control group. The black line represents the median of the group and the median (interquartile range) baseline and post-intervention endurance times are indicated. 
TABLE 3 Comparison of the variation in dyspnoea, daily steps, SGRQ, HADS, lung function, 6MWD and 1-RM between intervention and control groups

\begin{tabular}{|c|c|c|c|}
\hline & Pulmonary rehabilitation group & Control group & p-value \\
\hline Subjects $\mathrm{n}$ & 18 & 19 & \\
\hline \multicolumn{4}{|l|}{ Dyspnoea } \\
\hline$\Delta \mathrm{mMRC}$ & $0(-1-0)$ & $0(0-1)$ & $<0.001$ \\
\hline \multicolumn{4}{|l|}{ Daily physical activity } \\
\hline$\Delta$ Daily steps (total) & $752(-694-1814)$ & $-138(-830-208)$ & 0.02 \\
\hline \multicolumn{4}{|l|}{ SGRQ } \\
\hline$\Delta$ Symptoms & $-10(-22-0)$ & $0(-8-6)$ & 0.04 \\
\hline$\Delta$ Activity & $-11(-17--7)$ & $0.8(-0.8-12)$ & $<0.001$ \\
\hline$\Delta \mathrm{lmpact}$ & $-5(-12-0.2)$ & $0.2(-4-5)$ & 0.05 \\
\hline$\Delta$ Total & $-8(-16-2)$ & $2(-4-5)$ & 0.002 \\
\hline \multicolumn{4}{|l|}{ HADS } \\
\hline$\Delta \mathrm{FEV}_{1} \mathrm{~L}$ & $-0.05(-0.09-0.04)$ & $-0.03(-0.08-0.05)$ & 0.76 \\
\hline$\Delta \mathrm{FEV}_{1} \%$ & $-2(-5-2)$ & $-3(-4-4)$ & 0.59 \\
\hline$\Delta D \mathrm{LCO} \mathrm{mmHg}$ & $-0.22(-0.76-0.46)$ & $0(-0.89-0.17)$ & 0.88 \\
\hline$\Delta D\llcorner\mathrm{LO} \%$ & $-1(-7-3)$ & $0(-6-0.8)$ & 0.77 \\
\hline$\triangle 6 M W D$ & $59(13-81)$ & $20(-12-30)$ & 0.002 \\
\hline \multicolumn{4}{|l|}{ Muscle strength } \\
\hline$\Delta 1$-RM quadriceps $\%$ & $39(20-70)$ & $4(0-17)$ & $<0.001$ \\
\hline$\Delta 1$-RM hamstrings $\%$ & $82(53-127)$ & $-4(-9-6)$ & $<0.001$ \\
\hline$\Delta 1$-RM biceps $\%$ & $30(14-33)$ & $0(0-8)$ & $<0.001$ \\
\hline$\Delta 1-\mathrm{RM}$ arm abductors $\%$ & $29(4-50)$ & $0(-10-0)$ & $<0.001$ \\
\hline$\Delta 1$-RM pectorals $\%$ & $33(13-79)$ & $0(-5-8)$ & $<0.001$ \\
\hline
\end{tabular}

Data are presented as median (interquartile range), unless otherwise stated. SGRQ: St George's Respiratory Questionnaire; HADS: Hospital Anxiety and Depression Scale; 6MWD: 6-min walking distance; 1-RM: one-repetition maximum; TDI: Transitional Dyspnoea Index; mMRC: modified Medical Research Council dyspnoea scale; FEV1: forced expiratory volume in $1 \mathrm{~s} ; D$ Lco: diffusing capacity of the lung for carbon monoxide.

\section{Daily physical activity}

Overall, $75 \%$ of the patients $(61 \%$ in the pulmonary rehabilitation group versus $89 \%$ of controls; $\mathrm{p}=0.12)$ had daily physical activity below the recommended level (<10000 steps per day) [19]. By the end of the pulmonary rehabilitation programme, the intervention group demonstrated an improvement in daily physical activity (table 3 ).

\section{St George's Respiratory Questionnaire}

All patients had an impaired health-related quality of life at baseline. An important improvement in the SGRQ total score was observed in the pulmonary rehabilitation group, with a mean (95\% CI) reduction of $10.2(-16--4.5)$ points. This improvement was also significant (>4 units) for each domain (figure 4). Moreover, in an inter-group comparison, the improvements in the intervention group were also significant for all domains (table 3).

\section{Hospital Anxiety and Depression Scale}

Anxiety, quantified using the HADS scale, was frequent, occurring in 19 (51\%) subjects (eight (44\%) in the pulmonary rehabilitation group versus 11 (58\%) controls; $\mathrm{p}=0.63$ ). At baseline, symptoms of depression were present in $15(41 \%)$ patients: seven $(39 \%)$ in the pulmonary rehabilitation group and eight $(42 \%)$ in the control group $(\mathrm{p}=0.89)$.

A comparison of patients before and after pulmonary rehabilitation indicated a reduction in the median (interquartile range) score of depression symptoms from 5 (3-9) to 4 (1-7) $(\mathrm{p}=0.03)$. There was also a trend towards improvements in depression and total HADS score when comparing the pulmonary rehabilitation and control groups. No difference was observed in anxiety levels (table 3 ). 


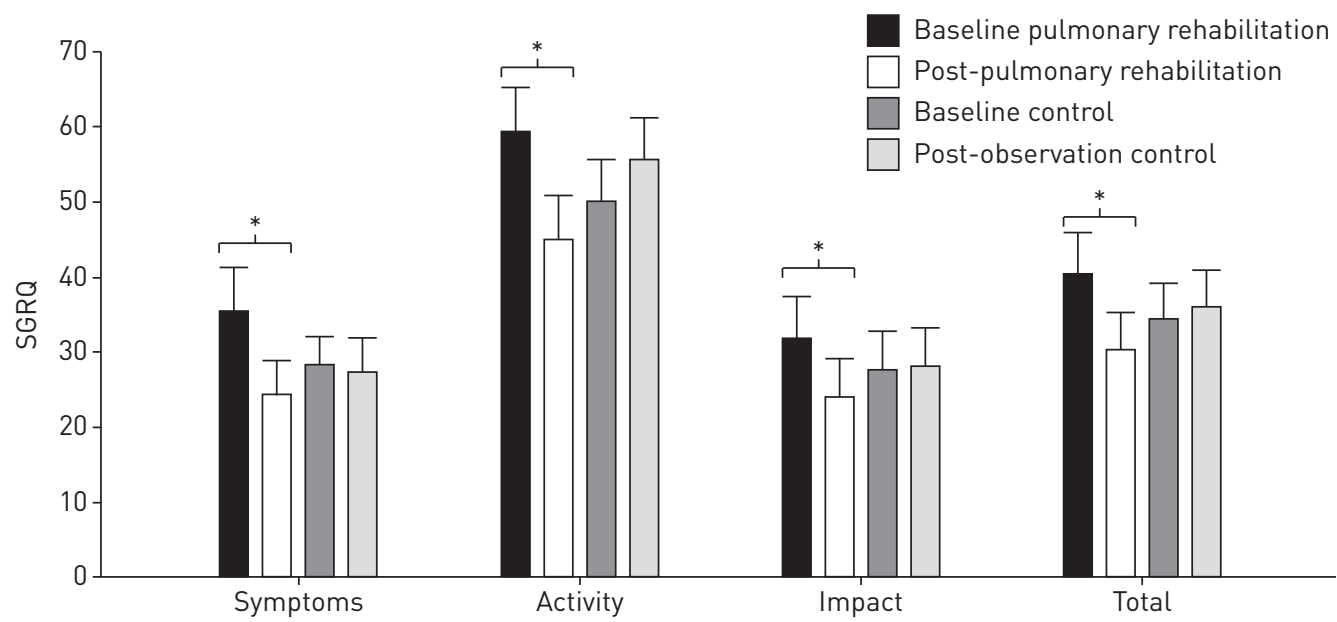

FIGURE 4 Health-related quality of life as measured by variation in St George's Respiratory Questionnaire (SGRQ) domains before and after pulmonary rehabilitation. *: $p<0.05$.

\section{Pulmonary function tests}

The most frequent patterns identified in baseline pulmonary function tests (PFTs) were: 1) obstruction in $51 \%$ of patients ( $44 \%$ of the intervention group versus $58 \%$ of controls; $p=0.63$ ); 2) reduced diffusing capacity of the lung for carbon monoxide in $51 \%$ of patients ( $50 \%$ of the intervention group versus $53 \%$ of controls; $\mathrm{p}=0.87$ ); and 3 ) air trapping in $27 \%$ of patients (33\% of the intervention group versus $21 \%$ of controls; $\mathrm{p}=0.48$ ). Normal lung function was observed in $30 \%$ of patients (33\% of the intervention group versus $26 \%$ controls; $\mathrm{p}=0.92$ ). There was no change in PFTs after pulmonary rehabilitation (table 3 ).

\section{6-min walk test}

At baseline, most patients had a preserved 6-min walking distance (6MWD) within predicted values, with a median of $517 \mathrm{~m}$. Oxygen desaturation $(>4 \%)$ during the $6 \mathrm{MWT}$ was observed in $35 \%$ of patients $(33 \%$ of the intervention group versus $37 \%$ of controls; $\mathrm{p}=0.9)$.

After pulmonary rehabilitation, there was an increase of $59 \mathrm{~m}$ in the 6MWD. The observed benefit remained significant when compared with the variation in the control group (table 3 ). The intervention group also presented a decrease in dyspnoea by the end of the test $(-1 \pm 2$ versus $0 \pm 2 ; \mathrm{p}<0.05)$. Oxygen desaturation did not change with the intervention.

\section{One-repetition maximum}

At baseline, muscle strength was greater in three of the five tested muscles in the control group (table E2). The pulmonary rehabilitation group exhibited improvements in strength in all of the evaluated muscles when compared with the controls (table 3).

\section{Correlations}

Endurance time improvements correlated most strongly with mMRC $(\mathrm{r}=-0.56 ; \mathrm{p}=0.02)$, peak $V^{\prime} \mathrm{O}_{2}$ $(\mathrm{r}=0.68 ; \mathrm{p}=0.002)$, dyspnoea $(\mathrm{r}=-0.53 ; \mathrm{p}=0.02)$ and leg discomfort at isotime $(\mathrm{r}=-0.65 ; \mathrm{p}=0.004)$ during the CWR exercise test (figure E4).

\section{Safety}

No pneumothorax or other serious adverse events related to pulmonary rehabilitation were observed during the programme. Only one patient discontinued pulmonary rehabilitation for a reason related to the intervention (knee pain during exercise that was later diagnosed as an old meniscus lesion).

\section{Discussion}

To our knowledge, this is the first clinical trial to investigate the effects of a pulmonary rehabilitation programme for LAM. In patients with LAM, pulmonary rehabilitation yielded the following: 1) a notable improvement in exercise capacity, observed in both endurance time during the CWR exercise test and walking distance in the $6 \mathrm{MWT}$; 2) augmented peak $V^{\prime} \mathrm{O}_{2}$; 3) reduced dyspnoea; 4) increased daily physical activity; 5) improved health-related quality of life; and 6) enhanced muscle strength. A trend towards improved symptoms of depression was also observed. The programme was safe, well tolerated and had a high rate of adherence. 
When investigating the suggested mechanisms underlying the improvement observed in the endurance time, we found that this outcome was not related to ventilatory, cardiovascular or gas exchange variables. The absence of changes in those parameters, associated with a reduction in RER isotime and dyspnoea, a trend towards reduced leg discomfort at isotime, an augmented peak $V^{\prime} \mathrm{O}_{2}$ and isotime and an increase in muscle strength after pulmonary rehabilitation, suggests that this improvement was related to peripheral muscle adaptation with an enhanced oxidative capacity. This is relevant because: 1) it confirms that the exercise limitation in patients with LAM is not exclusively ventilatory; and 2) it demonstrates that exercise training-induced peripheral muscle adaptation leads to an increased exercise capacity and symptom reduction. The substantial gain of strength observed in the 1-RM test for all trained muscles confirms that the strength training was effective and reinforces the hypothesis that the increase in the endurance time was related to peripheral muscle adaptation. We also observed an improvement in daily physical activity after pulmonary rehabilitation, in terms of both total and moderate-to-vigorous intensity exercise.

Exercise duration improved on both the CWR exercise test and 6MWT. We observed a median increase in the endurance time of $169 \mathrm{~s}(44 \%)$ after pulmonary rehabilitation, which is considered clinically relevant $(>100 \mathrm{~s}$ and $20 \%)[17,18,20]$ and comparable to the values obtained in two previous studies of COPD that reported average gains of $198 \pm 352 \mathrm{~s}$ and $144 \pm 36 \mathrm{~s}(43 \pm 10 \%)$ [20,21]. At an alpha error of 0.05 , our results had a power of $76 \%$ for the difference observed in the intervention group endurance time and of $92 \%$ for the variation observed in the between-group comparison. The improvement in the endurance time in the intervention group remained significant even when the two outliers identified in this group were removed from the analysis (data not shown). Another interesting finding was that the mean difference in 6MWD in the intervention group was $54 \mathrm{~m}$ (95\% CI 33-74 m), with a lower boundary above $30 \mathrm{~m}$, the value considered to discriminate a minimally important clinical difference in this test [22, 23]. This variation was superior to that observed in a meta-analysis of COPD patients, which reported a mean difference of $45 \mathrm{~m}$ (95\% CI 33-55 m) in the 6MWD after pulmonary rehabilitation [24].

Dyspnoea improved in all TDI domains, except for the functional impairment domain. The median variation in the total TDI score was three; notably, the literature states that a one-point difference in TDI is already clinically relevant [25]. The dramatic improvement observed in the quality of life, with an average SGRQ total score reduction of 10.2 (95\% CI -16--4.5), was even better than that reported in a recent meta-analysis of COPD patients, which found an average reduction of 6.9 (95\% CI -9.3--4.5) in SGRQ total score [24]. This was the first intervention for LAM that was able to induce clinically relevant changes in SGRQ. In the MILES trial, sirolimus led to improvement on the EuroQOL instrument compared with placebo, but the groups did not differ in terms of SRGQ, even though patients had baseline SGRQ values similar to those in our study [26]. Although our study did not observe a difference in anxiety, it was also the first intervention to demonstrate a trend towards a reduction in symptoms of depression in LAM.

Despite our important findings, our study has limitations that should be addressed. The impossibility of randomising the intervention groups, which was based on geographical issues, raised concern that the groups could differ in terms of baseline characteristics. However, we demonstrated that the groups were well balanced in terms of major clinical characteristics, lung function and exercise capacity. The muscle strength at baseline was lower in the pulmonary rehabilitation group compared with controls. It is not possible to exclude that this fact might have favoured the greater increase in muscle strength that was observed in the intervention group. However, we considered this less probable since the difference between groups was small and there was no correlation between baseline 1-RM values and muscle strength variation in the study population. Another possible limitation was related to the high number of ineligible patients in our population. Nevertheless, we were able to assure the representativeness of our sample by demonstrating that the baseline characteristics of patients in the present study were similar to those of a previous epidemiological study published by our group [27]. Although this was a single-centre study, it was conducted at a reference centre and included patients from all regions of Brazil and with all degrees of disease severity (eleven patients had moderate or severe obstruction), thus, it is reasonable to generalise the study results for all Brazilian patients with LAM. Whereas most studies train their patients in the same modality used for evaluation [20,28], we trained our patients on a treadmill and evaluated them on a cycle ergometer. This might have led to a reduced effect in our primary outcome, as the changes in oxidative metabolism that occur after regular physical activity are muscle specific, and therefore, although walking and cycling both involve lower limb training, the workload imposed upon the quadriceps is much greater while cycling [29]. Another characteristic of rehabilitation studies is that the intervention makes it impossible to blind the participants and professionals involved in the training. To avoid a potential placebo effect, we included objective variables such as the endurance time in the protocol.

In conclusion, our study has demonstrated the safety and efficacy of pulmonary rehabilitation for patients with LAM. We believe that the new evidence presented here should direct health professionals to consider the inclusion of any patient with LAM and an impaired exercise capacity in a pulmonary rehabilitation programme, 
given the absence of serious adverse events and the improvements observed in exercise capacity, dyspnoea and health-related quality of life. For less severe patients, it would be reasonable to stimulate exercise practice even outside the setting of a pulmonary rehabilitation programme, although this was not tested in the present study. For patients with severe or progressive disease, pulmonary rehabilitation should be added as an adjunctive therapy to pharmacological treatment, since rehabilitation was the first intervention to show an improvement in exercise capacity, and also yielded additional benefits in terms of symptoms relief and quality of life.

\section{Acknowledgements}

The authors thank all the professionals involved in the pulmonary rehabilitation programme (Physical Therapy Division, University of São Paulo Medical School, São Paulo, Brazil) and colleagues from the Pulmonary Function and Interstitial Lung Diseases groups (Pulmonary Division, Heart Institute (InCor), University of São Paulo Medical School, São Paulo, Brazil) for their collaboration in this study.

\section{References}

1 McCormack FX, Travis WD, Colby TV, et al. Lymphangioleiomyomatosis: calling it what it is: a low-grade, destructive, metastasizing neoplasm. Am J Respir Crit Care Med 2012; 186: 1210-1212.

2 McCormack FX, Inoue Y, Moss J, et al. Efficacy and safety of sirolimus in lymphangioleiomyomatosis. $N$ Engl J Med 2011; 364: 1595-1606.

3 Baldi BG, Albuquerque AL, Pimenta SP, et al. Exercise performance and dynamic hyperinflation in lymphangioleiomyomatosis. Am J Respir Crit Care Med 2012; 186: 341-348.

4 Spruit MA, Singh SJ, Garvey C, et al. An official American Thoracic Society/European Respiratory Society statement: key concepts and advances in pulmonary rehabilitation. Am J Respir Crit Care Med 2013; 188: e13-e64.

5 Nici L, Donner C, Wouters E, et al. American Thoracic Society/European Respiratory Society statement on pulmonary rehabilitation. Am J Respir Crit Care Med 2006; 173: 1390-1413.

6 Johnson SR, Cordier JF, Lazor R, et al. European Respiratory Society guidelines for the diagnosis and management of lymphangioleiomyomatosis. Eur Respir J 2010; 35: 14-26.

7 Haskell WL, Lee IM, Pate RR, et al. Physical activity and public health: updated recommendation for adults from the American College of Sports Medicine and the American Heart Association. Med Sci Sports Exerc 2007; 39: 1423-1434.

8 Fanelli A, Cabral AL, Neder JA, et al. Exercise training on disease control and quality of life in asthmatic children. Med Sci Sports Exerc 2007; 39: 1474-1480.

9 Ries AL, Bauldoff GS, Carlin BW, et al. Pulmonary rehabilitation: joint ACCP/AACVPR evidence-based clinical practice guidelines. Chest 2007; 131: Suppl., 4S-42S.

10 Storer TW. Exercise in chronic pulmonary disease: resistance exercise prescription. Med Sci Sports Exerc 2001; 33: Suppl., S680-S692.

11 Kraemer WJ, Adams K, Cafarelli E, et al. American College of Sports Medicine position stand. Progression models in resistance training for healthy adults. Med Sci Sports Exerc 2002; 34: 364-380.

12 Mahler DA, Weinberg DH, Wells CK, et al. The measurement of dyspnea. Contents, interobserver agreement, and physiologic correlates of two new clinical indexes. Chest 1984; 85: 751-758.

13 Jones PW, Quirk FH, Baveystock CM. The St George's Respiratory Questionnaire. Respir Med 1991; 85: Suppl. B, $25-31$.

14 Zigmond AS, Snaith RP. The hospital anxiety and depression scale. Acta Psych Scand 1983; 67: 361-370.

15 American Thoracic Society, American College of Chest Physicians. ATS/ACCP statement on cardiopulmonary exercise testing. Am J Respir Crit Care Med 2003; 167: 211-277.

16 Laviolette L, O'Donnell DE, Webb KA, et al. Performance during constant work rate cycling exercise in women with COPD and hyperinflation. COPD 2009; 6: 340-351.

17 O'Donnell DE, Flüge T, Gerken F, et al. Effects of tiotropium on lung hyperinflation, dyspnoea and exercise tolerance in COPD. Eur Respir J 2004; 23: 832-840.

18 Casaburi R. Factors determining constant work rate exercise tolerance in COPD and their role in dictating the minimal clinically important difference in response to interventions. COPD 2005; 2: 131-136.

19 Tudor-Locke C, Bassett DR Jr. How many steps/day are enough? Preliminary pedometer indices for public health. Sports Med 2004; 34: 1-8.

20 Laviolette L, Bourbeau J, Bernard S, et al. Assessing the impact of pulmonary rehabilitation on functional status in COPD. Thorax 2008; 63: 115-121.

21 O’Donnell DE, McGuire M, Samis L, et al. General exercise training improves ventilatory and peripheral muscle strength and endurance in chronic airflow limitation. Am J Respir Crit Care Med 1998; 157: 1489-1497.

22 Holland AE, Spruit MA, Troosters T, et al. An official European Respiratory Society/American Thoracic Society technical standard: field walking tests in chronic respiratory disease. Eur Respir J 2014; 44: 1428-1446.

23 Singh SJ, Puhan MA, Andrianopoulos V, et al. An official systematic review of the European Respiratory Society/ American Thoracic Society: measurement properties of field walking tests in chronic respiratory disease. Eur Respir J 2014; 44: 1447-1478.

24 McCarthy B, Casey D, Devane D, et al. Pulmonary rehabilitation for chronic obstructive pulmonary disease. Cochrane Database Syst Rev 2015; 2: CD003793.

25 Witek TJ Jr, Mahler DA. Minimal important difference of the transition dyspnoea index in a multinational clinical trial. Eur Respir J 2003; 21: 267-272.

26 Swigris JJ, Lee HS, Cohen M, et al. St. George's Respiratory Questionnaire has longitudinal construct validity in lymphangioleiomyomatosis. Chest 2013; 143: 1671-1678.

27 Baldi BG, Freitas CS, Araujo MS, et al. Clinical course and characterisation of lymphangioleiomyomatosis in a Brazilian reference centre. Sarcoidosis Vasc Diffuse Lung Dis 2014; 31: 129-135.

28 Porszasz J, Emtner M, Goto S, et al. Exercise training decreases ventilatory requirements and exercise-induced hyperinflation at submaximal intensities in patients with COPD. Chest 2005; 128: 2025-2034.

29 Man WD, Soliman MG, Gearing J, et al. Symptoms and quadriceps fatigability after walking and cycling in chronic obstructive pulmonary disease. Am J Respir Crit Care Med 2003; 168: 562-567. 